\title{
Market price of risk implied by Asian-style electricity options and futures
}

\author{
Rafał Weron* \\ Hugo Steinhaus Center for Stochastic Methods, Institute of Mathematics and Computer Science, \\ Wrocław University of Technology, 50-370 Wroctaw, Poland
}

Received 22 April 2007; received in revised form 21 May 2007; accepted 22 May 2007

Available online 16 June 2007

\begin{abstract}
In this paper we propose a jump-diffusion type model which recovers the main characteristics of electricity spot price dynamics in the Nordic market, including seasonality, mean-reversion and spiky behavior. We show how the calibration of the market price of risk to actively traded futures contracts allows for efficient valuation of Nord Pool's Asian-style options written on the spot electricity price. Furthermore, we study the evolution of the market price of risk (and the risk premium) over a three year time period and compare the obtained results with those reported in the literature.
\end{abstract}

(C) 2007 Elsevier B.V. All rights reserved.

JEL classification: C51; G13; L94; Q40

Keywords: Electricity price modeling; Asian option; Market price of risk; Risk premium; Derivatives pricing

\section{Introduction}

Dramatic changes to the structure of the power sector have taken place over the past two decades, including the deregulation and introduction of competitive markets. In a competitive market utilities cannot automatically pass costs to customers. This has the effect of increasing uncertainty and risks borne by the investors. Electricity has changed from a primarily technical business, to one in which the product is treated in much the same way as any other commodity. However, already in the first years after the emergence of deregulated power markets it became

\footnotetext{
The data and Matlab codes for reproducing all the results are available upon request.

* Tel.: +48 71320 3530; fax: +48 713202654.

E-mail address: rafal.weron@pwr.wroc.pl.
} 
obvious that for the valuation of electricity derivatives we cannot simply rely on models developed for financial or other commodity markets. The need for realistic models of price dynamics capturing the unique characteristics of electricity and adequate derivatives pricing techniques became apparent.

In this paper we study the Nordic power market with a special emphasis on Asian-style options written on the spot electricity price that were traded at Nord Pool. We discuss the issue of the market price of risk, which is essential for pricing derivatives written on the spot electricity price, and show how its calibration to actively traded futures contracts allows for efficient valuation of the Asian-style options.

The paper is structured as follows. In Section 2 we provide a concise overview of the Nordic power exchange Nord Pool and its products, including the Asian-style option. In Section 3 we briefly recall the stylized facts of electricity markets that have to be taken into account when modeling spot prices. In Section 4 we discuss the pros and cons of the most promising modeling approaches and show how electricity derivatives can be priced within selected models. In particular, we discuss the importance of the market price of risk (and the risk premium) for pricing electricity derivatives. Since Nord Pool's Asian-style options were written on the spot system price, in Section 5 we propose an adequate mean reverting jump-diffusion type model of the spot price dynamics. Next, we calculate the market prices of risk implied by Asian-style options and actively traded futures contracts and show how the latter can be used for pricing the options. Finally, we study the long run evolution of the market price of risk (and the risk premium) and compare the obtained results with those reported in the literature. In Section 6 we conclude and summarize the results.

\section{Nord Pool and Asian-style electricity options}

Developed power markets typically exhibit spot and derivatives trading. In the beginning it is the spot market that dominates. With time, as more and more participants join in and start to actively hedge (and speculate), the volumes of traded derivatives outnumber those of spot transactions. However, it is the spot system price that is still the most influential. In particular, it is the underlying instrument of a vast majority of derivatives.

The spot electricity market is actually a day-ahead market. A classical spot market would not be possible, since the system operator needs advanced notice to verify that the schedule is feasible and lies within transmission constraints. In fact, in the U.S. day-ahead markets are usually called forward markets, while real-time balancing markets are termed spot markets.

At the Nordic power exchange, Nord Pool, every day is divided into 24 hourly spot contracts. Before noon, the previous day, all participants send in their bids for each hour. The system price is calculated as the equilibrium point for the aggregated supply and demand curves and for each of the $24 \mathrm{~h}$. It is a theoretical price in the sense that it assumes that no congestions will occur and is the same in the whole Nordic area (Nord Pool, 2006). Besides the physically settled spot contracts traded on the Elspot market, Nord Pool offers financially settled derivatives on its Eltermin market: futures, forwards (standardized but not marked-to-market), options and other specialized contracts (like the CdFs, for hedging price differentials between the system and area/zonal prices).

A particularly interesting example of an electricity derivative instrument is the Asian-style option that was traded at Nord Pool. It is interesting for at least two reasons. Firstly, to our knowledge it is the only Asian-style exchange traded contract. Secondly, despite its appeal as a natural hedging instrument on very volatile markets, Nord Pool ceased listing it due to low liquidity. Whether this was a consequence of the pricing problems, inadequate contract specification, marketing or simply bad luck remains an open question. 
Options trading at Nord Pool commenced on October 29, 1999. Two types of contracts were offered: European-style Electric/Power Options (EEO or EPO) written on the exchange traded standardized forward contracts and Asian-style Electric/Power Options (AEO or APO). By definition, an Asian-style option is exercised and settled automatically, in retrospect, against the price of the underlying instrument during a given period. AEO options were settled against the arithmetic average of the spot system price in the settlement period that started after the option expired. This is in contrast to typical financial Asian options which are settled against the average price during the trading period. However, such a 'financial' specification would not make sense in electricity markets due to seasonality patterns.

Nord Pool's AEO options had the same delivery (settlement) periods as the simultaneously traded futures block contracts (i.e. futures with four week delivery periods). There were three AEO series listed for trading and clearing with the three nearest block futures contracts acting as 'underlying' Eltermin market contracts. A new option series was listed on the first trading day after a block contract had gone to delivery. We have to note, however, that the Asian-style options were not written on the futures block contracts, only the delivery periods coincided. The AEO's underlying instrument was the spot electricity price. Consequently, a call/put AEO option was inthe-money if the difference between the average system spot price during the delivery period and the strike price was positive/negative. Settlement took place the day after the last trading day in the delivery period. There was no payment if the option was at-the-money or out-of-the-money.

\section{Stylized facts}

In this section we briefly review the so-called stylized facts of the Nordic market and electricity markets in general. This will enable us to pinpoint the essential properties of spot prices and thus give us sufficient grounds for proposing an adequate model of price dynamics.

It is well known that electricity demand exhibits seasonal fluctuations (Eydeland and Wolyniec, 2003; Pilipovic, 1998; Weron, 2006). They mostly arise due to changing climate conditions (temperature, number of daylight hours) and business activities. In some countries also the supply side (e.g. hydro units in Norway) shows seasonal variations in output. These seasonal fluctuations in demand and supply translate into the seasonal behavior of spot electricity prices. A typical behavior for the Nordic countries - high prices in winter time followed by low prices during the summers - is presented in Fig. 1. Interestingly, not only the mean but also the variance/ volatility is time dependent (for an analysis of the volatility at Nord Pool see e.g. Simonsen, 2005). The latter effect may be due to the fact that temperatures, as well as other weather phenomena, also display seasonal variations in the variance (Tol, 1996).

In addition to strong seasonality on the annual, weekly and daily level, spot electricity prices exhibit infrequent, but large spikes, see Fig. 1. These spikes are normally quite short-lived, and as soon as the weather phenomenon or outage is over, prices fall back to a normal level (Kaminski, 1999; Perello et al., 2006; Weron et al., 2004). These temporary price escalations account for a large part of the total variation of changes in spot prices. And we have to stress that the price of electricity is far more volatile than that of other commodities normally noted for extreme volatility. In fact, heavy-tailed models often yield a very good fit to electricity spot price returns (Eberlein and Stahl, 2003; Weron, 2006).

Finally, energy spot prices are in general regarded to be mean reverting (Pindyck, 1999). Among all financial time series spot electricity prices are perhaps the best example of antipersistent data (Huisman et al., 2007; Park et al., 2006; Simonsen, 2003; Weron, 2002). Importantly, these results are not an artifact of the seasonality nor the spikes. Although, the Hurst 


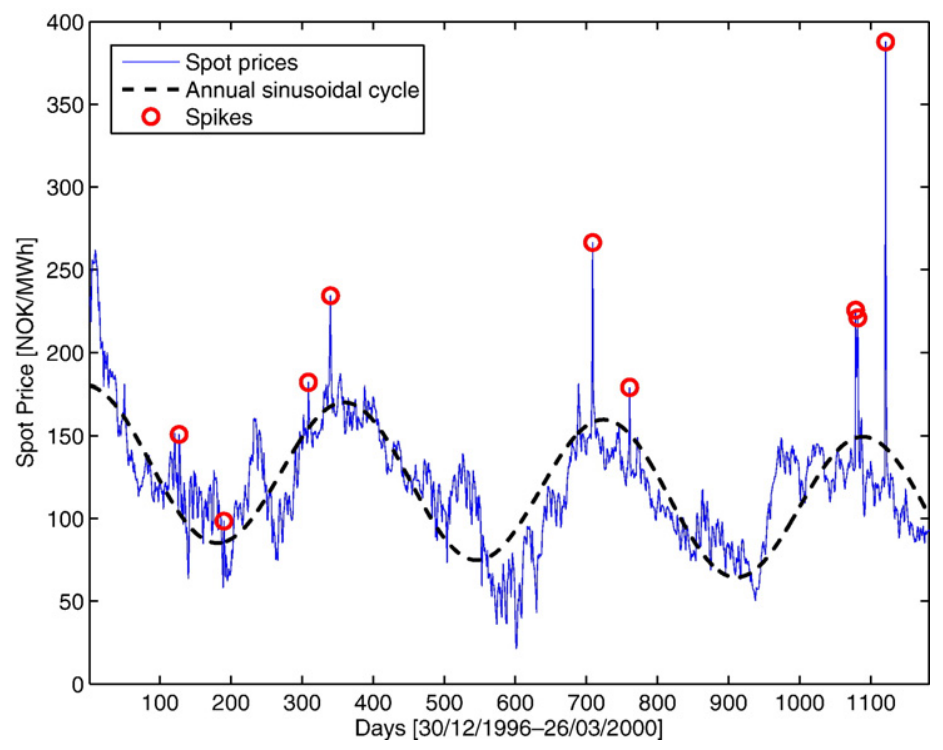

Fig. 1. Nord Pool market daily average system price since December 30, 1996 until March 26, 2000. Circles denote spikes identified during the calibration procedure (see text for details). Superimposed on the plot is an approximation of the annual cycle by a sinusoid with a linear trend.

exponent $H$ generally slightly increases after removal of seasonality and/or spikes, it is still significantly lower than 0.5 . For time intervals of less than $24 \mathrm{~h}$, however, $H$ is above 0.5 , indicating persistence on the intra-daily level.

\section{Modeling approaches}

There have been several attempts at modeling spot electricity prices in competitive markets. The applied methodologies may be broadly divided into six classes (Weron, 2006):

- production-cost (or cost-based) models,

- equilibrium (or game theoretic) approaches,

- fundamental (or structural) methods,

- statistical (or technical analysis) approaches,

- artificial intelligence-based (or non-parametric) techniques,

- and quantitative (or stochastic, econometric, reduced-form) models.

For recent reviews consult also Amjady and Hemmati (2006), Bunn (2004), Conejo et al. (2005), Eydeland and Wolyniec (2003), Misiorek et al. (2006), Shahidehpour et al. (2002), Skantze and Ilic (2001) and Ventosa et al. (2005).

Production-cost models simulate the operation of generating units aiming to satisfy demand at minimum cost. They have the capability to forecast prices on an hour-by-hour, bus-by-bus level. However, they ignore strategic bidding practices, hence, are not well suited for today's competitive markets. Equilibrium approaches may be viewed as generalizations of cost-based models amended with strategic bidding considerations. They may give good insight into whether prices will be above marginal costs and how this might influence the players' outcomes. But they 
pose problems if more quantitative conclusions have to be drawn. Furthermore, a substantial modeling risk is present as the players, their potential strategies, the ways they interact and the set of payoffs have to be defined up-front.

Fundamental models describe price dynamics by modeling the impact of important physical and economic factors on the price of electricity. The functional associations between fundamental drivers - loads, weather conditions, system parameters, etc. - are postulated and the inputs are modeled and predicted, often via statistical, econometric or non-parametric techniques. Unfortunately, fundamental models rely on a large number of generally not easily available data variables (e.g. Vahviläinen and Pyykkönen (2005) calibrated as many as 27 fundamental variables in their model of the Nordic market) and the utilized variables are typically collected only with low - weekly, monthly, quarterly - frequency. Consequently, 'pure' fundamental models are not particularly well suited for day-to-day market operations.

Statistical and artificial intelligence-based (AI-based) techniques aim at finding the optimal model for electricity prices in terms of its forecasting capabilities. The former are either direct applications of the statistical techniques of load forecasting or power market implementations of econometric models. Most popular methods include multivariate regression, time series models and smoothing techniques. AI-based techniques, on the other hand, model price processes via non-parametric tools such as artificial neural networks (ANNs), expert systems, fuzzy logic and support vector machines. They tend to be flexible and can handle complexity and non-linearity. This makes them promising for short-term predictions, but their complexity unnecessarily complicates derivatives pricing.

Finally, there are quantitative models, which characterize the statistical properties of electricity prices over time, with the ultimate objective of derivatives valuation and risk management. Based on the type of market in focus, the stochastic techniques can be divided into two main classes: spot and forward price models. The former provide a proper representation of the dynamics of spot prices which, in the wake of deregulation of power markets, becomes a necessary tool for trading purposes. Their main drawback is the difficulty encountered when pricing derivatives, i.e. the identification of the risk premium linking spot and forward prices (or those of other derivatives). On the other hand, forward price models allow for pricing of derivatives in a straightforward manner (Audet et al., 2004; Clewlow and Strickland, 2000). However, they too have their limitations; most importantly, the lack of data that can be used for calibration and the inability to derive the properties of spot prices from the analysis of forward curves. As the Asianstyle options analyzed in this study are written on the spot system price, in what follows we will focus on quantitative spot price models.

\subsection{Quantitative models for the spot price}

In the econometric approaches, modeling concentrates on the price process form and parameters. Typically the spot electricity price $P_{\mathrm{t}}$ is assumed to follow some kind of a jump-diffusion process, obtained as a special case of the following general stochastic differential equation (SDE):

$$
\mathrm{d} P_{\mathrm{t}}=\mu\left(P_{\mathrm{t}}, t\right) \mathrm{d} t+\sigma\left(P_{\mathrm{t}}, t\right) \mathrm{d} W_{\mathrm{t}}+\mathrm{d} q\left(P_{\mathrm{t}}, t\right)
$$

where $W_{\mathrm{t}}$ is a Wiener process. The drift term $\mu\left(P_{\mathrm{t}}, t\right)$ usually forces mean-reversion to a stochastic or deterministic long-term mean at a constant rate. However, other specifications are also used. For example, Borovkova and Permana (2006) proposed the drift to be given by a potential function, which forces the price to return to its seasonal level after an upward jump. Interestingly, it allows the 
rate of mean-reversion to be a continuous function of the distance from this level. The volatility term $\sigma\left(P_{\mathrm{t}}, t\right)$ is often, for simplicity, set to a constant. However, empirical evidence suggests that electricity prices exhibit heteroscedasticity (Karakatsani and Bunn, 2004; Simonsen, 2005).

The process $q\left(P_{\mathrm{t}}, t\right)$ is a pure jump process (typically independent of $W_{\mathrm{t}}$ ) with given intensity and severity, e.g. a compound Poisson process (Čižek et al., 2005). After a jump the price is forced back to its normal level by the mean-reversion mechanism. However, a high rate of mean-reversion, required to force the price back to its normal level after a jump, would lead to a highly overestimated value of this parameter for prices outside the 'spike regime'. To circumvent this, Escribano et al. (2002) allowed signed jumps. But if these randomly follow each other, the spike shape has obviously a very low probability of being generated. Geman and Roncoroni (2006) suggested using meanreversion coupled with upward and downward jumps, with the direction of a jump being dependent on the current price level. Benth et al. (2007) modeled the spot electricity price by a sum of nonGaussian Ornstein-Uhlenbeck processes, each of which is reverting to a mean at a different speed and having pure jump processes with only positive jumps as sources of randomness. Weron et al. (2004) postulated that a positive jump should always be followed by a negative jump of (approximately) the same size to capture the rapid decline of electricity prices after a spike. On the daily level, i.e. when analyzing average daily prices, this approach seems to be a good approximation since spikes typically do not last more than a day. In order to obtain pricing formulas for electricity forwards Lucia and Schwartz (2002) even dropped out the jump component and only considered one- and two-factor mean reverting diffusion models.

The very good fit of heavy-tailed distributions to electricity price returns (Eberlein and Stahl, 2003; Mugele et al., 2005), and the $\alpha$-stable law in particular (Rachev et al., 2004), could be the motive for substituting the Wiener process in Eq. (1) by ( $\alpha$-stable, NIG, hyperbolic, etc.) Lévy motion. In such a case, the jump component $q\left(P_{\mathrm{t}}, t\right)$ would not be needed in specification (1), as Lévy motion generally leads to purely discontinuous ('jumpy') price paths (Cont and Tankov, 2003; Janicki and Weron, 1994). A similar approach was suggested by Benth and Saltyte-Benth (2004) for modeling oil and natural gas spot prices. However, as Weron (2006) observed, Lévy motion just by itself misses two important features of electricity markets. Namely, it cannot recover the spikes which are extreme price changes generally coupled in 'up-jump'-'down-jump' pairs and it does not allow for control of the intensity of the jumps, a property that might be crucial in some power markets.

Yet another line of reasoning leads to considering that a jump in the electricity price is simply a change to another regime (the spike regime) that follows a different stochastic process than the socalled base regime. The switching mechanism can be assumed to be governed by a random variable that follows a Markov chain with two (or more) possible states (Bierbrauer et al., 2004; de Jong, 2006; Huisman and Mahieu, 2003; Mount et al., 2006). Clearly the probability of being (and also staying) in the base regime is supposed to be much higher than that for the spike regime. Regime switching models are also able to consider spikes that last for more than just one time period (an hour, a day), without the disadvantage of slow mean-reversion after a jump. However, Weron (2006) has shown for a number of models that in terms of the statistical properties of simulated spot price trajectories they are inferior to jump-diffusions. Hence, in the empirical analysis that follows we will utilize a jump-diffusion model.

\subsection{Derivatives, risk premia and the market price of risk}

The standard approach to pricing a derivative security is to construct a portfolio that will perfectly replicate the payout of the contract. This generally involves storing a certain amount of the underlying instrument for the duration of the contract. Then the argument of the absence of 
arbitrage forces the price of this derivative to be equal to the price of the replicating portfolio. In the case of electricity, however, the no-arbitrage approach fails. Electricity itself cannot be stored efficiently, while storage possibilities of energy sources (water, gas, oil, coal) are also very limited, financially demanding and generally available only to the generators (Weron, 2006).

Though the spot price is not an asset that can be used in a replicating portfolio, futures and forward contracts, on the other hand, are regular financial contracts that can be traded and used in a replicating strategy. Consequently, derivatives written on these contracts could be priced with the no-arbitrage principle. The question is whether information contained in the prices of these derivatives and the forward prices themselves could be used when evaluating derivatives on the spot price.

For commodities, the relationship between spot and forward prices (and between prices of futures or forward contracts with different maturities) is often explained in terms of the convenience yield. The convenience yield is defined as the premium to a holder of a physical commodity as opposed to a futures or forward contract written on it (Eydeland and Wolyniec, 2003; Geman, 2005). The relationship between the spot price $P_{\mathrm{t}}$ and the forward price $F_{t, T}$ for delivery at time $T$ is then given by

$$
F_{t, T}=P_{\mathrm{t}} e^{\left(r_{\mathrm{t}}-y_{\mathrm{t}}\right)(T-t)}
$$

where $r_{\mathrm{t}}$ is the riskless interest rate and $y_{\mathrm{t}}$ is the convenience yield (in general: a stochastic process) prevailing at time $t$.

The important question is whether the notion of the convenience yield does make sense in the context of electricity. If the commodity is non-storable, can we quantify the benefit from holding the commodity, not to mention the storage cost? As there is no consensus on this issue, we propose to turn to a related, but more general notion of the risk premium. The risk premium is the reward for holding a risky investment rather than a risk-free one. More precisely, the risk premium is the difference between the spot price forecast, which is the best estimate of the going rate of electricity at some specific time in the future, and the forward price, i.e. the actual price a trader is prepared to pay today for delivery of electricity in the future (Botterud et al., 2002; Diko et al., 2006; Hirshleifer, 1989; Pindyck, 2001; Weron, 2006):

$$
R P=\mathbb{E}_{\mathrm{t}}\left(P_{\mathrm{T}}\right)-F_{t, T},
$$

where the expectation $\mathbb{E}$ is taken today (time $t$ ) with respect to the 'real-world' or 'risky' probability measure and concerns the price at a future date $T$. Note, that the futures price $F_{t, T}$ is, in fact, the expectation of $P_{\mathrm{T}}$ with respect to the 'risk-neutral' or 'risk-adjusted' measure.

There is mixed evidence on the sign and variability of the risk premium in power markets. Generally, the premium can be both positive and negative; it can vary throughout the year or even throughout the day. The results can also differ from market to market. To some extent, however, the mixed evidence has been caused by inconsistent definitions of the risk premium. In particular, some authors use the notion of the forward premium (also called forward risk premium) defined as the negative of the risk premium (see e.g. Bessembinder and Lemmon, 2002; Longstaff and Wang, 2004; Villaplana, 2003):

$$
F P=-R P=F_{t, T}-\mathbb{E}_{\mathrm{t}}\left(P_{\mathrm{T}}\right) .
$$

Yet others use the term risk premium, but define it like the forward premium - as the difference between the forward price and the expected spot price (Benth et al., 2006; Bessembinder, 1992; Eydeland and Wolyniec, 2003; Geman, 2005). 
In order to price derivatives we need to take into account the risk premium observable in the market. In the context of spot price models this means that we have to calibrate these models not only to spot prices but also to forward (or in general: derivative) prices and in this way infer the risk premium. There is, however, a difficulty in this approach. It stems from the fact that in empirical applications $\mathbb{E}_{\mathrm{t}}\left(P_{\mathrm{T}}\right)$ is not a well defined object. The expected value operates on a random variable (here: $P_{\mathrm{T}}$ ) defined on a specific probability space $(\Omega, \mathcal{F}, \mathcal{P})$. Just by analyzing one historical price trajectory it is hard to gain any consensus on what actually is the probability space. We have to make some approximations and/or assumptions. For instance, Geman and Vasicek (2001) and Longstaff and Wang (2004) analyzed differences between the futures price today and the actual (not the expected today) spot price in the future, i.e. $F_{t, T}-P_{\mathrm{T}}$, while Botterud et al. (2002) approximated $\mathbb{E}_{\mathrm{t}}\left(P_{\mathrm{T}}\right)$ by the futures price one day before expiry. Alternatively, we can postulate a certain model of spot price dynamics and compute the expectation within this model. Naturally, $\mathbb{E}_{\mathrm{t}}\left(P_{\mathrm{T}}\right)$ becomes then model dependent.

In the next section we will follow the latter approach. In fact, we will present the results not in terms of the risk premium, but rather in terms of the market price of risk, a notion popular in the financial mathematics literature. The market price of risk (often denoted by $\lambda$ ) is the difference between the drift in the original 'risky' probability measure $\mathcal{P}$ and the drift in the 'risk-neutral' measure $\mathcal{P}^{\lambda}$ in the stochastic differential equation governing the price dynamics.

\section{Empirical analysis}

Having described the stylized facts, the pricing approaches proposed in the literature and the AEO option contract specifications we are ready to put forward the pricing model. For the empirical analysis we have chosen the Nord Pool market daily average system prices $P_{\mathrm{t}}$ from December 30, 1996 until March 26, 2000, see Fig. 1. The choice of this particular time period is not incidental - 1996 was a dry year with exceptionally high electricity prices and the first part of 2000 is used for testing the model. March 26, 2000 is the last day of the four week settlement period for the AEO-GB0300 options, i.e. AEO options which had the same delivery period February 28 till March 26 - as the simultaneously traded GB0300 futures block contracts. We could not use data beyond March 26, 2000 because later that year trading was very scarce with the last transaction involving AEO options taking place on February 2, 2001.

\subsection{Data preprocessing}

For modeling the annual cycle we follow the same line of approach as Pilipovic (1998) and Geman and Roncoroni (2006), who fit spot electricity prices with a proper sinusoidal function, i.e. a combination of an affine function and one or two sine functions with distinct periods. Although the seasons do not follow a symmetric sine (a fact that is reinforced by basic climatology, see Oliver and Hidore, 2001) the approximation is reasonable for this data, see Fig. 1 where the Nord Pool market daily average system price and the approximation of its annual cycle by a sine function with a linear trend is plotted. In some markets, however, the seasonality is less pronounced and more harmonics are necessary to obtain an acceptable fit. For instance, Cartea and Figueroa (2005) used a Fourier series of order five to fit the annual seasonality pattern of the England and Wales power market. Wavelet decomposition could be utilized instead (Stevenson, 2001; Weron, 2006). It offers yet greater flexibility, however, its medium- and long-term modeling/forecasting applicability is limited.

An alternative and more general modeling approach is to use a piecewise constant function of a one year period, where for each month one tries to determine an average value out of the whole 
analyzed time series (Bhanot, 2000; Lucia and Schwartz, 2002). Although flexible, this method lacks smoothness, which may have negative impact on statistical inference of the deseasonalized price process. This could be circumvented by using dummies for the middle of the month coupled with smooth interpolation between them. Yet, another approach was proposed by Weron et al. (2001). It consists of fitting a function of a one year period, which is determined by taking the average (over the years in the sample) of the smoothed rolling volatility. The method yields a smooth estimate of the annual seasonal component, in the sense that the component is constant only during a one day (or one hour; depending on the sampling frequency) period.

For the sake of parsimony, in what follows we will use the sinusoid fit only. Namely, the annual cycle will be approximated by:

$$
S_{\mathrm{t}}=A \sin \left(\frac{2 \pi}{365}(t+B)\right)+C t .
$$

Originally the parameters were estimated in a two step procedure. First, a least squares fit was used to obtain initial estimates of all three parameters: $A, B$ and $C$. Then the time shift parameter $B$ was chosen such as to maximize the $p$-value of the Bera-Jarque test for normality (Jarque and Bera, 1987) applied to the deseasonalized and spikeless log-prices (see Section 5.2). The original calibration procedure was substituted later by a more robust technique: all the parameters were estimated in a single step by minimizing the product of both (i) the squared difference between the price $P_{\mathrm{t}}$ and the seasonal component $S_{\mathrm{t}}$ and (ii) the Bera-Jarque statistics: $B J=n\left[\frac{1}{6}\right.$ skewness $\left.^{2}+\frac{1}{24}(\text { kurtosis }-3)^{2}\right]$, where $n$ is the sample size. For the time period December 30, 1996-March 26, 2000 the estimates are: $\hat{A}=45.04, \hat{B}=94.98$ and $\hat{C}=-0.0284$. Note, that estimating parameters so that a given goodness-of-fit statistic is minimized is a standard procedure in statistics, see e.g. Chapter 13 in Čižek et al. (2005). Equivalently the $p$-value could be maximized, or minimized depending on the specification of the null hypothesis.

Like demand, spot electricity prices are not uniform throughout the week. The intra-week and intra-day variations of demand caused by different level of working activities translate into periodical fluctuations in electricity prices. However, in the present analysis we do not address the issue of intra-day variations and analyze only daily average prices as the AEO options are settled against the average system price during a four week period. We deal with the intra-week variations by removing the weekly median-based seasonal component $s_{\mathrm{t}}$ (for numerical details see Weron, 2006), as the median is more robust to outliers than the mean. In the following sections we model the logarithm of the deseasonalized prices (with respect to the weekly and annual cycles; in short: deseasonalized log-prices):

$$
d_{\mathrm{t}}=\log \left(P_{\mathrm{t}}-s_{\mathrm{t}}-S_{\mathrm{t}}\right) .
$$

The time series $d_{\mathrm{t}}$ is plotted in the top panel of Fig. 2 .

\subsection{The jump-diffusion model}

Despite their rarity, price spikes are the very motive for designing insurance protection against electricity price movements. This is one of the most serious reasons for including jump components in realistic models of electricity spot price dynamics. Reflecting the fact that on the daily scale spikes typically do not last more than one time point (i.e. one day), like in Weron et al. (2004), we let a positive jump be always followed by a negative jump of about the same magnitude. This is achieved by letting $d_{\mathrm{t}}$ be a sum of a mean reverting stochastic part $X_{\mathrm{t}}$ and an 

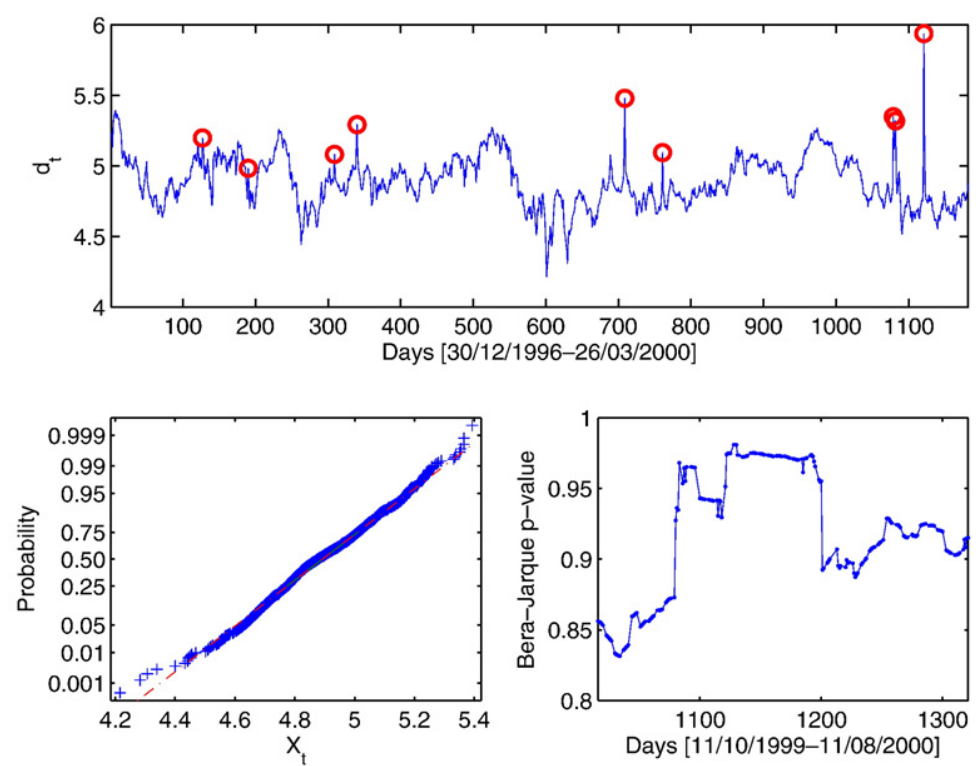

Fig. 2. Top panel: The logarithm of the deseasonalized spot price, i.e. $d_{t}$, for the period December 30, 1996 until March 26 , 2000. Like in Fig. 1, circles denote spikes. Bottom left panel: The normal probability plot of the stochastic part $X_{\mathrm{t}}$ for the same period. The crosses form a straight line indicating a Gaussian distribution. Bottom right panel: The $p$-values of the Bera-Jarque test for normality for the stochastic part $X_{\mathrm{t}}$ and time intervals ending on October 11, 1999 through August 11, 2000. The hypothesis of normality cannot be rejected at any reasonable level.

independent jump component. Following the standard approach put forward in Section 4.1, the jump component $q\left(P_{\mathrm{t}}, t\right)$ is modeled by a compound Poisson process (Čižek et al., 2005) with increments of the form $\mathrm{d} q\left(P_{\mathrm{t}}, t\right)=J_{\mathrm{t}} \mathrm{d} q_{\mathrm{t}}$, where $J_{\mathrm{t}}$ is a random variable responsible for the spike severity and $q_{\mathrm{t}}$ is a homogeneous Poisson process with intensity $\kappa$.

The choice of $J_{\mathrm{t}}$ and $\kappa$ depends on the definition of the spike. Price spikes are generally defined as prices that surpass a specified threshold for a brief period of time, but it is difficult to gain any consensus on what that threshold or time interval should be (for a discussion see Weron, 2006). We adopt the following: a spike is an increase in the price (formally: an increase in $d_{\mathrm{t}}$ ) exceeding $H=2.5$ standard deviations of all price changes (i.e. $d_{\mathrm{t}}-d_{t-1}$ ) followed by a decrease in the price. The threshold level is set arbitrarily. The usual threshold $H=3$ results in only six spikes in the series plotted in Fig. 1, while $H=2.5$ yields nine spikes and captures all 'obvious' peaks seen in the plot of $d_{\mathrm{t}}$, see the top panel of Fig. 2. Like in Cartea and Figueroa (2005) the extraction of the spikes from the original series is performed iteratively — the algorithm filters the series and removes all price changes greater than $H$ standard deviations of all price changes at that specific iteration. The algorithm is repeated until no further spikes can be filtered. After the spikes are extracted, the price $d_{\mathrm{t}}$ at these time points is replaced by the arithmetic average of the two neighboring prices yielding the deseasonalized and 'spikeless' log-prices $X_{\mathrm{t}}$.

The extracted nine spikes do not allow for a sound statistical analysis of the spike severity nor intensity. For the sake of simplicity we let $J_{\mathrm{t}}$ be a log-normal random variable $\log J_{\mathrm{t}} \sim N\left(\mu, \rho^{2}\right)$, although the empirical spike size distribution seems to have heavier tails (with power-law decay, but not fitted too well by a Pareto law). Since $J_{\mathrm{t}}$ represents the size of the logarithm of the spike magnitude it is truncated at the maximum price attainable in the market (5000 NOK in the studied 
period; the price cap is changed from time to time to reflect market situation, for details see the Nord Pool website: www.nordpool.com) to ensure a finite mean of the price process $P_{\mathrm{t}}$. Moreover, we let $q_{\mathrm{t}}$ be a homogeneous Poisson process with intensity $\kappa$. Again the sample suggests that this may not be the best choice - six spikes were observed in winter and only one in each of the other seasons. However, estimating a periodic intensity function (of a non-homogeneous Poisson process) using only nine time points involves high model risk and most probably would lead to large estimation errors. For the whole period depicted in Fig. 1 maximum likelihood estimates of the jump component are $\hat{\mu}=-1.27, \hat{\rho}=0.65$ and $\hat{\kappa}=0.0076$.

Putting all the facts together, the jump-diffusion model has the following form:

$$
d_{\mathrm{t}}=J_{\mathrm{t}} \mathrm{d} q_{\mathrm{t}}+X_{\mathrm{t}} \quad \text { or } \quad P_{\mathrm{t}}=s_{\mathrm{t}}+S_{\mathrm{t}}+e^{J_{\mathrm{t}} \mathrm{d} q_{\mathrm{t}}+X_{\mathrm{t}}},
$$

where $X_{\mathrm{t}}$ is the stochastic component. The exponent in the last term of Eq. (7) reflects the fact that the marginal distribution of $X_{\mathrm{t}}$ is approximately Gaussian, whereas the deseasonalized, with respect to the weekly and annual cycles, and 'spikeless' spot prices can be very well described by a log-normal distribution, i.e. their logarithms are approximately Gaussian. The fit is surprisingly good. For time intervals starting on December 30, 1996 and ending on November 1, 1999 through March 26, 2000 the $p$-values of the Bera-Jarque test for normality range from 0.84 to 0.98 giving no grounds to reject the hypothesis of normality at any reasonable level, see also the bottom panels in Fig. 2. On the other hand, the $p$-values for the 'spiky' deseasonalized log-prices $d_{\mathrm{t}}$ are generally less than 0.0001 , allowing us to reject normality practically at any level. Since the marginal distribution of $X_{\mathrm{t}}$ is approximately Gaussian we are tempted to propose the simplest mean reverting model with Gaussian marginals, i.e. the Vasicek model.

The Vasicek (1977) model, also referred to as an arithmetic Ornstein-Uhlenbeck process, was originally proposed for describing interest rate dynamics. It is governed by the following SDE:

$$
\mathrm{d} X_{\mathrm{t}}=\left(\alpha-\beta X_{\mathrm{t}}\right) \mathrm{d} t+\sigma \mathrm{d} W_{\mathrm{t}}=\beta\left(L-X_{\mathrm{t}}\right) \mathrm{d} t+\sigma \mathrm{d} W_{\mathrm{t}},
$$

where $W_{\mathrm{t}}$ is a Wiener process. This is a one-factor model that reverts to the mean $L=\frac{\alpha}{\beta}$ with $\beta$ being the magnitude of the speed of adjustment. The second term is responsible for the volatility of the process. The conditional distribution of $X$ at time $t$ is normal with mean $E\left[X_{\mathrm{t}}\right]=\frac{\alpha}{\beta}+\left(X_{0}-\frac{\alpha}{\beta}\right) e^{-\beta t}$ and variance $\operatorname{Var}\left[X_{\mathrm{t}}\right]=\frac{\sigma^{2}}{2 \beta}\left(1-e^{-2 \beta t}\right)$. These relations imply that $E\left[X_{\mathrm{t}}\right] \rightarrow L=\frac{\alpha}{\beta}$ as $t \stackrel{\infty}{\rightarrow}$. Starting at different points the Vasicek model trajectories tend to reverse to the long run mean and stabilize in the corridor defined by the standard deviation of the process. The parameters of the mean reverting process (8) can be estimated using a number of techniques, including maximum likelihood (ML) and the Generalized Method of Moments (GMM). These two approaches yield slightly different parameters, however, they both lead to roughly the same long-term level $L=\frac{\alpha}{\beta}$ and volatility $\sigma$. Since ML estimates exhibit a more robust behavior we have decided to use them, instead of the initially applied GMM. For the time period December 30, 1996-March 26, 2000 the ML estimates are: $\hat{\alpha}=0.2191, \hat{\beta}=0.0449$ and $\hat{\sigma}=0.0499$, implying $\hat{L}=4.8797$. For comparison, the GMM estimates for the same data are: $\hat{\alpha}=0.2374, \hat{\beta}=0.0486$ and $\hat{\sigma}=0.0500$, yielding nearly the same longterm level $\hat{L}=4.8848$.

\subsection{The market price of risk}

Since we calibrate the stochastic part, and hence the whole model, using spot market (i.e. 'risky', not 'riskless') data we need to include the risk premium before we start pricing options or other derivatives. For now, we assume that the market price of risk $\lambda$ is a deterministic constant 
and, hence, a predictable process. Note, that we can relax this restriction and let $\lambda$ be a deterministic function of time. By virtue of the Girsanov theorem there exists a probability measure $\mathcal{P}^{\lambda}$, equivalent to the original 'risky' probability measure $\mathcal{P}$, such that the process

$$
W_{\mathrm{t}}^{\lambda} \equiv W_{\mathrm{t}}+\int_{0}^{t} \lambda(s) \mathrm{d} s=W_{\mathrm{t}}+\lambda_{\mathrm{t}},
$$

is a Wiener process under $\mathcal{P}^{\lambda}$ (Musiela and Rutkowski, 1997). Using Itô calculus we can write:

$$
\begin{aligned}
\mathrm{d} X_{\mathrm{t}} & =\beta\left(L-X_{\mathrm{t}}\right) \mathrm{d} t+\sigma \mathrm{d} W_{\mathrm{t}}=\beta\left(L-X_{\mathrm{t}}\right) \mathrm{d} t+\sigma \mathrm{d}\left(W_{\mathrm{t}}^{\lambda}-\lambda t\right) \\
& =\beta\left(\frac{\alpha-\lambda \sigma}{\beta}-X_{\mathrm{t}}\right) \mathrm{d} t+\sigma \mathrm{d} W_{\mathrm{t}}^{\lambda}
\end{aligned}
$$

Under the new measure $X_{\mathrm{t}}$ follows the same Vasicek-type of SDE with the same speed of mean-reversion $\beta$ and the same volatility $\sigma$, but a different long-term mean $\tilde{L}=\frac{\alpha-\lambda \sigma}{\beta}$.

Standard arbitrage arguments with two derivative assets allow us to conclude that $\mathcal{P}^{\lambda}$ can be treated as the risk-adjusted or risk-neutral measure (Lucia and Schwartz, 2002). This means that if we estimated the market price of risk then we would know the dynamics of the stochastic component $X_{\mathrm{t}}$ in the riskless world and, hence, we could price any derivatives on the spot electricity price. We have to mention, though, that no analytical formulas are known for the Nord Pool variant of the Asian option within the presented model. In what follows we will thus use Monte Carlo simulations. The pricing of a particular option for a given day will be based on the average payout from five thousand simulated price trajectories of the price process $P_{\mathrm{t}}$. All model parameters - representing the seasonal, spike and stochastic components - will be estimated from a time series ending on the previous day.
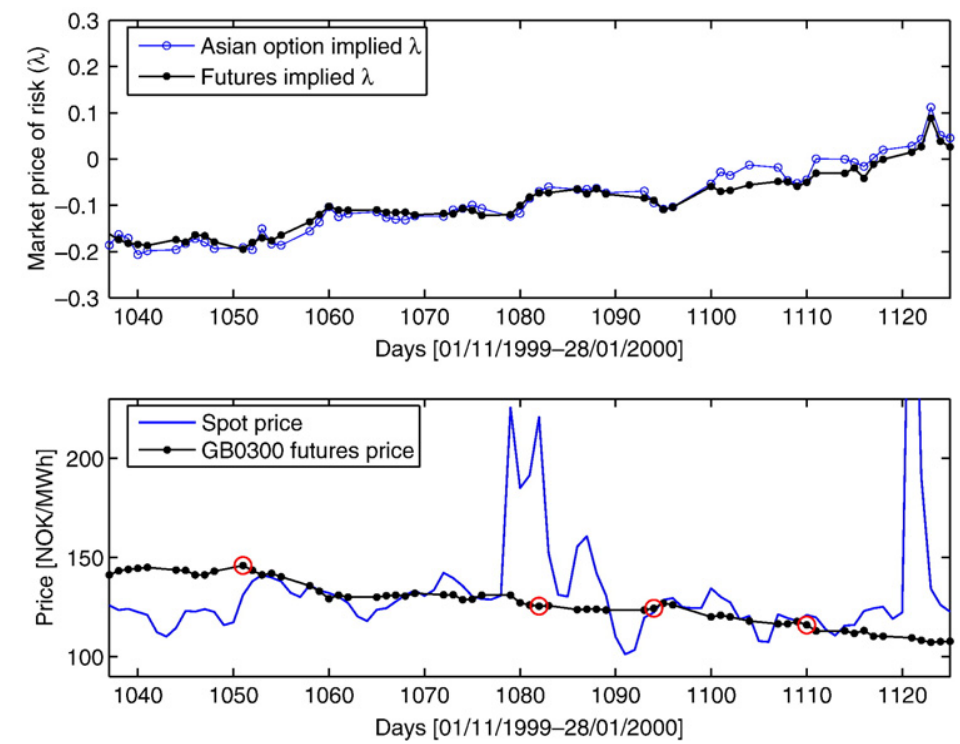

Fig. 3. Top panel: The market prices of risk, $\lambda$ 's, implied from AEO-GB0300 Asian-style options and GB0300 futures. Bottom panel: Spot electricity and GB0300 futures prices during the period November 1, 1999-January 28, 2000. Circles denote the four days for which the pricing results are presented in Fig. 4. 
One way of finding the market price of risk is to imply it from option prices. This technique resembles recovery of the implied volatility in the Black-Scholes model. The procedure consists of finding $\lambda^{*}$ such that it minimizes a chosen score function, here the mean absolute percentage error between the market and model option prices. The market prices are in fact averages of the bid and ask offers. We could not use transaction data since on some days no transactions took place. We run a bounded minimization routine, with $\lambda \in[-0.5,0.5]$, based on Golden Section search and parabolic interpolation (see Matlab documentation for details). This procedure is time consuming - yet much faster than the earlier used unconstrained simplex search - since at every minimization time step the option price has to be evaluated using Monte Carlo simulations. The results for AEO call options are shown in Fig. 3. Apparently the implied market price of risk is not constant but rather is an increasing function of time $t$, i.e. a decreasing function of time to maturity $\tau=T-t$. In a similar study Cartea and Figueroa (2005) and Lucia and Schwartz (2002) calibrated and used for pricing derivatives a constant $\lambda$. Our results show that using the simplified constant form of the market price of risk is too restrictive and may lead to large pricing errors.

The choice of $\lambda$ uniquely determines the equivalent martingale measure under which derivatives pricing is performed. Therefore calibrating it to futures prices should do the same job. Indeed, it does. The procedure is analogous to that for the options, with the only difference that now for a given day the model is calibrated to one futures price instead of the option prices for four different strikes used previously. The results can be seen in the top panel of Fig. 3, where the market prices of risk implied from AEO-GB0300 Asian-style options and GB0300 futures are depicted. The similarity of these two curves allows us to propose the following adaptive scheme for pricing the AEO options. For each selected day the seasonal, spike and stochastic components are estimated from the time series of spot prices ending on the previous day. Then the market price of risk is calibrated to GB0300 futures prices for today and is subsequently used for pricing the AEO options. Note, that at Nord Pool, futures are much more liquid instruments than options and,
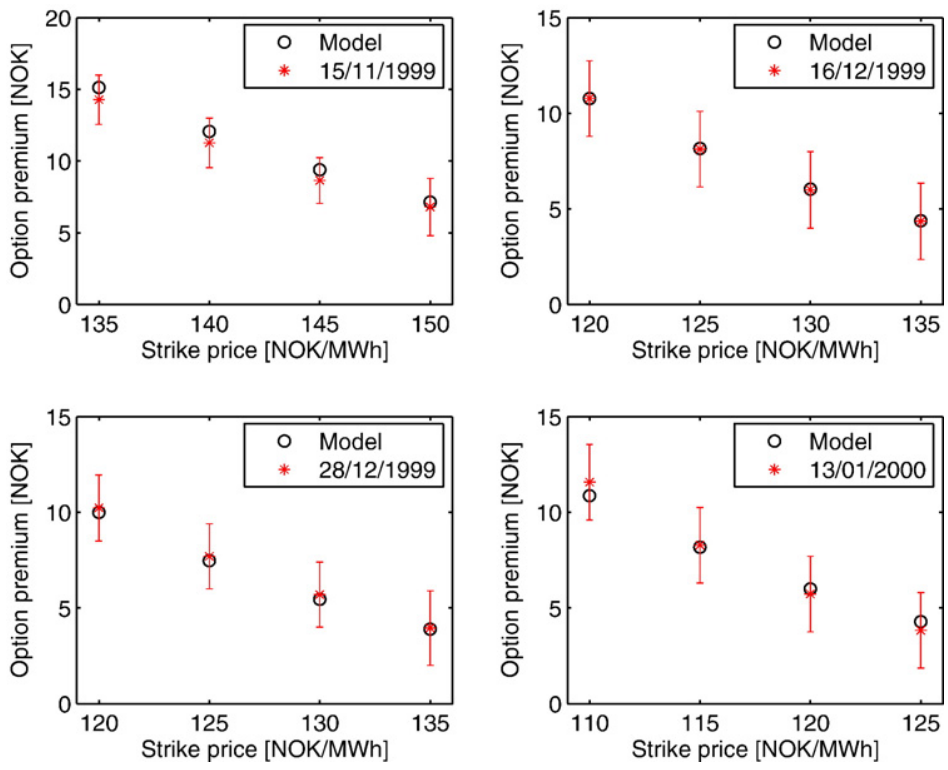

Fig. 4. Model $(O)$ and market $(*)$ prices of AEO call options. In all cases the model prices lie in the interval spanned by the bid and ask offers (vertical bars). 
hence, allow for a more frequent and precise calibration of $\lambda$. Sample results of this procedure are shown in Fig. 4. They confirm the usefulness of the approach. Although the fit is not always perfect, in all cases the model prices lie in the interval spanned by the bid and ask offers.

\subsection{Long-term evolution of the market price of risk}

In the period depicted in Fig. 3 the market price of risk can be pretty well approximated by a linear function. This fact could potentially be utilized for forecasting future values of $\lambda$ and, hence, pricing Asian-style options. Another interesting feature is the similarity of (the negative of) the market price of risk and the futures price - compare the top and bottom panels in Fig. 3. Linear regression of the options implied $\lambda$ on the futures price yields a very good fit with $R^{2}=0.95$. The futures implied $\lambda$ gives an even better fit with $R^{2}=0.96$. Dependence between the market price of risk and the futures price is not something unexpected. After all, the futures price is a (possibly biased) forecast of the spot electricity price during delivery. When the futures price moves, the prices of all derivatives with the same or similar delivery period have to adjust accordingly. In particular, when the futures price decreases, the risk premium $R P=\mathbb{E}_{\mathrm{t}}\left(P_{\mathrm{T}}\right)-F_{t, T}$ and, hence, the market price of risk increase, as within our model the spot price forecast $\mathbb{E}_{\mathrm{t}}\left(P_{\mathrm{T}}\right)$ is a relatively stable process.

The pertinent question is, however, how universal are the two properties mentioned above. With this in mind we have expanded our study to cover a much longer time period than the one depicted in Fig. 3. Since options trading was scarce or even nonexistent outside this period we limited the analysis to futures contracts. For ease of comparison we decided to use a selection of block contracts, such that the trading periods of the contracts span the three year interval: spring 1998-spring 2001, see Fig. 5. Earlier dates could not be analyzed due to shortage of data available for calibration, later dates — because of fundamental changes in the market. In early

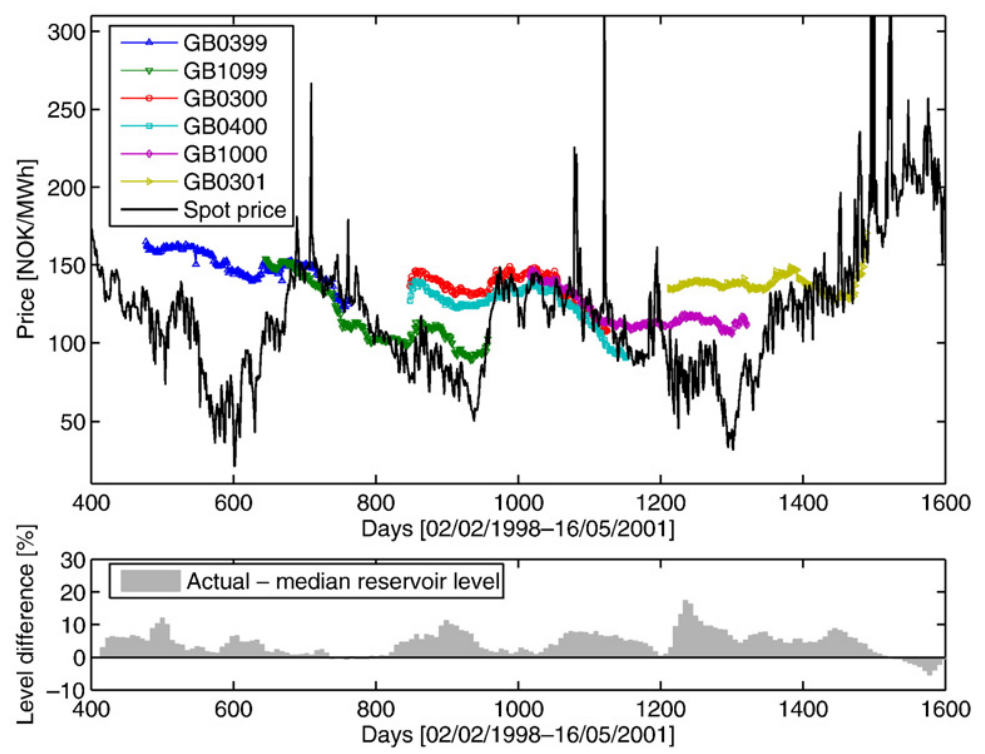

Fig. 5. Top panel: Block futures contracts (GBxxxx) and daily average spot system prices spanning a time period of over three years. Bottom panel: The difference (in percent) between the actual and median (for 1990-2003) reservoir levels in Norway. As long as the actual level is above the median, the spot prices behave 'normally'. When the actual level substantially drops below the median the prices increase, as in spring 2001. 
2001, owing to severe weather conditions, the water reservoir levels in Scandinavia dropped significantly below their long-term median level for the first time in a few years, see the bottom panel in Fig. 5. As hydro production is dominant in the Nord Pool region this had the long standing effect of very high prices during the whole year 2001.

Returning to the issue of linearity of $\lambda$, we can observe in Fig. 6 that - contrary to the previously studied period (days 1030-1130) - over a longer time horizon the market price of risk cannot be approximated by a linear function; compare the black solid circles for Asian-style options with the other curves. There are periods when a linear fit would be acceptable but, in general, a linear predictor does not yield good estimates of $\lambda$. Regarding the similarity of (the negative of) the market price of risk and the futures price, the empirical evidence over a longer time period is not that supportive, compare Figs. 5 and 6. Again, there are periods when the movements of $\lambda$ and the corresponding futures price are highly correlated but, in general, this property is not so strong as to provide a means of modeling the market price of risk via the futures price.

Fig. 6 delivers, however, other interesting observations. For most of the time $\lambda$ is (i) negative and (ii) increasing (or equivalently decreasing with time to maturity). A reasonable explanation for negative $\lambda$ is a higher incentive for hedging on the demand side relative to the supply side, because of the non-storability of electricity as compared to the (limited and costly but still existent) storage capabilities of fuel - especially water, but also coal, oil and gas. The negative $\lambda$ is consistent with the observations of Botterud et al. (2002) who found negative risk premia in the Nord Pool futures price data for a similar time period (but a slightly different definition of the risk premium, i.e. with $\mathbb{E}_{\mathrm{t}}\left(P_{\mathrm{T}}\right)$ approximated by the futures price one day before expiry), Geman and Vasicek (2001) who demonstrated that short-term (as opposed to long-term of the order of several years) forward contracts in the U.S. markets are upward biased estimators of spot prices observed at later dates and Longstaff and Wang (2004) who reported positive on average forward premia (i.e. negative risk premia) for very short-term (day-ahead) forward contracts in the PJM market.

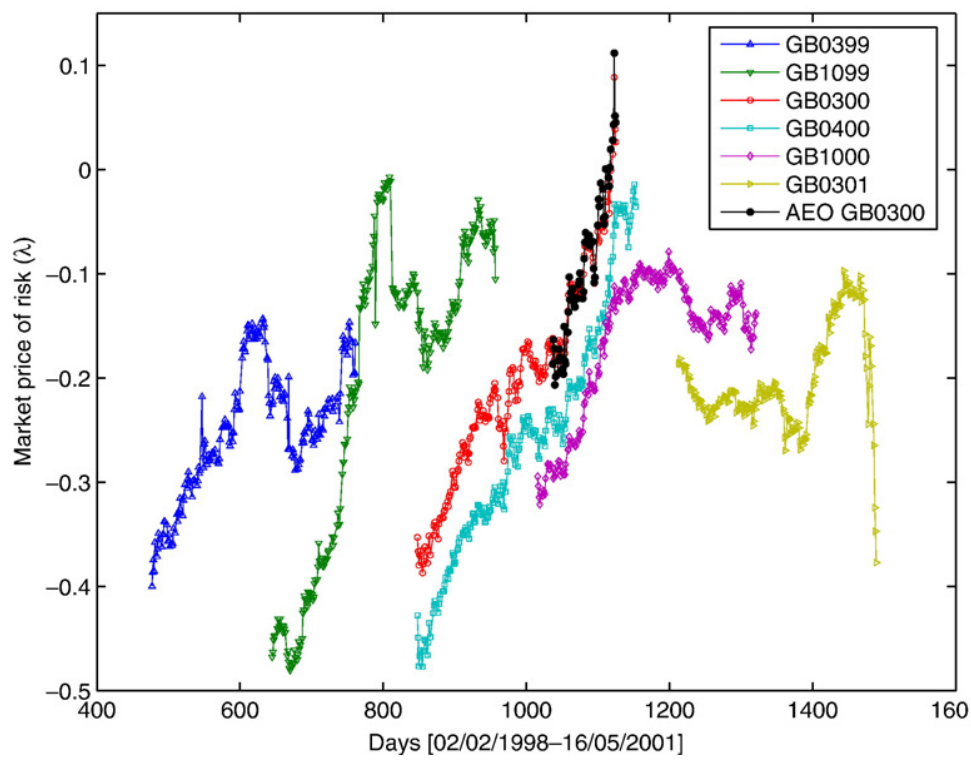

Fig. 6. Market prices of risk implied by block futures contracts (GBxxxx; see Fig. 5) and Asian-style options (AEOGB0300) spanning a time period of over three years. 
On the other hand, the increasing with time market price of risk is in agreement with the general equilibrium model of electricity spot and forward markets presented by Bessembinder and Lemmon (2002). In their model the risk premium is positive (i.e. the forward premium is negative or equivalently the futures price is a downward biased predictor of the future spot price) when expected power demand is low and demand risk is moderate. It decreases when either expected demand or demand variance is high, because of positive skewness in the spot electricity price distribution. As maturity of a futures contract approaches the uncertainty about the demand at delivery declines and, hence, the risk premium (and the market price of risk) increases. It even can become positive, as in late winter 1999/2000 (changes of sign of the forward premium were also reported by Bessembinder and Lemmon (2002) and Longstaff and Wang (2004) for the U.S. markets). Yet, in some periods this increasing tendency is stopped or even reversed. It seems that $\lambda$ decreases with time generally in periods when the spot prices are relatively low (days: 620-680, 810-870, 1200-1400; compare Figs. 5 and 6), but not necessarily the lowest in a given year. However, no clear seasonal pattern can be observed in the plot of the market price of risk.

Furthermore, the empirical evidence presented in Fig. 6 indicates that the prices of futures contracts with different maturities imply a similar time evolution of the market price of risk. The level of $\lambda$ may be different for different contracts, but its dynamic properties are preserved. This finding suggests that the market price of risk is not only a function of time but also of the delivery period, i.e. $\lambda=\lambda\left(t,\left\{T_{1}, T_{2}\right\}\right)$. However, for a given time $t$ the values of $\lambda$ for different deliveries are highly correlated and good approximations can be obtained simply by vertical translation of one of the curves.

\section{Conclusions}

In this paper we propose a model which recovers the main characteristics of electricity spot price dynamics, including seasonality, mean-reversion and spiky behavior. The seasonality is modeled by a sinusoidal function coupled with a median-based weekly component. Meanreversion is achieved through a Vasicek type stochastic differential Eq. (10). Finally, the spike formation mechanism is an independent compound Poisson process. After calibration of the market price of risk $\lambda$ to actively traded futures contracts, the model allows for efficient valuation of Nord Pool's Asian-style options written on the spot electricity price.

The market price of risk observed in the initially studied period (winter 1999/2000-spring 2000; see Fig. 3) exhibits two features potentially interesting in the context of forecasting future values of $\lambda$ - linearity in time and similarity to the negative of the futures price. To answer the question how universal are these two properties we have expanded our study to cover a much longer time period: spring 1998-spring 2001, see Figs. 5 and 6. In turned out that both are only local. There are periods when the movements of $\lambda$ and the corresponding futures price are highly correlated and linear but, in general, these properties are not so strong as to provide a means of forecasting $\lambda$.

The longer time period delivers, however, other interesting observations. Namely, for most of the time $\lambda$ is (i) negative and (ii) increasing (or equivalently decreasing with time to maturity). A reasonable explanation for negative $\lambda$ is a higher incentive for hedging on the demand side relative to the supply side, because of the non-storability of electricity as compared to the (limited and costly but still existent) storage capabilities of fuel. The negative $\lambda$ is consistent with the observations of Botterud et al. (2002), Geman and Vasicek (2001) and Longstaff and Wang (2004) who reported negative (on average) risk premia at Nord Pool and U.S. markets. On the other hand, the increasing with time market price of risk is in agreement with the general equilibrium model of Bessembinder and Lemmon (2002). 


\section{Acknowledgments}

The author would like to thank Alfred Müller, Ingve Simonsen, Richard Tol, Stefan Trück, Piotr Wilman and two anonymous referees for many helpful comments and suggestions. Thanks are due also to the participants of seminars at the Humboldt-Universität zu Berlin, University of Zürich, Weierstrass Institute, Wrocław University of Economics, and conference participants of Stochastic Finance 2004, Deutsche Bundesbank's 2005 Annual Fall Conference, European Electricity Market (EEM-05, EEM-06) and 2nd AMaMeF Conference (Advances in Mathematics of Finance, 2007).

\section{References}

Amjady, N., Hemmati, M., 2006. Energy price forecasting. IEEE Power \& Energy Magazine 20-29 (March/April).

Audet, N., Heiskanen, P., Keppo, J., Vehviläinen, I., 2004. Modeling electricity forward curve dynamics in the Nordic market. In: Bunn, D.W. (Ed.), Modelling Prices in Competitive Electricity Markets. Wiley, pp. 251-265.

Benth, F.E., Saltyte-Benth, J., 2004. The normal inverse Gaussian distribution and spot price modelling in energy markets. International Journal of Theoretical and Applied Finance 7 (2), 177-192.

Benth, F.E., Cartea, A., Kiesel, R., 2006. Pricing Forward Contracts in Power Markets by the Certainty Equivalence Principle: Explaining the Sign of the Market Risk Premium. SSRN Working Paper.

Benth, F.E., Kallsen, J., Meyer-Brandis, T., 2007. A non-Gaussian Ornstein-Uhlenbeck process for electricity spot price modeling and derivatives pricing. Applied Mathematical Finance 14 (2), 153-169.

Bessembinder, H., 1992. Systematic risk, hedging pressure, and risk premiums in futures markets. Review of Financial Studies 5 (4), 637-667.

Bessembinder, H., Lemmon, M., 2002. Equilibrium pricing and optimal hedging in electricity forward markets. Journal of Finance 57, 1347-1382.

Bhanot, K., 2000. Behavior of power prices: Implications for the valuation and hedging of financial contracts. Journal of Risk 2, 43-62.

Bierbrauer, M., Trück, S., Weron, R., 2004. Modeling electricity prices with regime switching models. Lecture Notes in Computer Science 3039, 859-867.

Borovkova, S., Permana, F.J., 2006. Modelling electricity prices by the potential jump-diffusion. In: Shiryaev, A.N., Grossinho, M.R., Oliveira, P.E., Esquivel, M.L. (Eds.), Stochastic Finance — 'Proceedings of StochFin2004'. Springer, pp. 239-264.

Botterud, A., Bhattacharyya, A.K., Ilic, M., 2002. Futures and spot prices - an analysis of the Scandinavian electricity market. Proceedings of North American Power Symposium, 2002, Tempe, Arizona.

Bunn, D.W. (Ed.), 2004. Modelling Prices in Competitive Electricity Markets. Wiley, Chichester.

Cartea, A., Figueroa, M.G., 2005. Pricing in electricity markets: a mean reverting jump diffusion model with seasonality. Applied Mathematical Finance 12 (4), 313-335.

Čižek, P., Härdle, W., Weron, R. (Eds.), 2005. Statistical Tools for Finance and Insurance. Springer, Berlin.

Clewlow, L., Strickland, C., 2000. Energy Derivatives - Pricing and Risk Management. Lacima Publications, London.

Conejo, A.J., Contreras, J., Espínola, R., Plazas, M.A., 2005. Forecasting electricity prices for a day-ahead pool-based electric energy market. International Journal of Forecasting 21 (3), 435-462.

Cont, R., Tankov, P., 2003. Financial Modelling with Jump Processes. Chapman \& Hall / CRC Press.

de Jong, C., 2006. The nature of power spikes: a regime-switch approach. Studies in Nonlinear Dynamics and Econometrics 10 (3) (Article 3).

Diko, P., Lawford, S., Limpens, V., 2006. Risk premia in electricity forward prices. Studies in Nonlinear Dynamics and Econometrics 10 (3) (Article 7).

Eberlein, E., Stahl, G., 2003. Both sides of the fence: a statistical and regulatory view of electricity risk. Energy Power Risk Management 8 (6), 34-38.

Escribano, A., Pena, J.I., Villaplana, P., 2002. Modelling Electricity Prices: International Evidence. Working Paper 02-27 Universidad Carlos III de Madrid.

Eydeland, A., Wolyniec, K., 2003. Energy and Power Risk Management. Wiley, Hoboken, NJ.

Geman, H., 2005. Commodities and Commodity Derivatives. Wiley, Chichester.

Geman, H., Roncoroni, A., 2006. Understanding the fine structure of electricity prices. Journal of Business 79 (3), $1225-1262$. 
Geman, H., Vasicek, O., 2001. Forwards and Futures on Non Storable Commodities: The Case of Electricity. Risk. August. Hirshleifer, D., 1989. Determinants of hedging and risk premia in commodity futures markets. Journal of Financial and Quantitative Analysis 24 (3), 425-434.

Huisman, R., Mahieu, R., 2003. Regime jumps in electricity prices. Energy Economics 25, 425-434.

Huisman, R., Huurman, C., Mahieu, R., 2007. Hourly electricity prices in day-ahead markets. Energy Economics 29 (2), $240-248$. Janicki, A., Weron, A., 1994. Simulation and Chaotic Behavior of $\alpha$-Stable Stochastic Processes. Marcel Dekker, New York. Jarque, C.M., Bera, A.K., 1987. A test for normality of observations and regression residuals. International Statistical Review 55, 163-172.

Kaminski, V. (Ed.), 1999. Managing Energy Price Risk. Risk Books, London.

Karakatsani, N., Bunn, D.W., 2004. Modelling the Volatility of Spot Electricity Prices. London Business School, EMG Working Paper.

Longstaff, F.A., Wang, A.W., 2004. Electricity forward prices: a high-frequency empirical analysis. Journal of Finance 59 (4), 1877-1900.

Lucia, J.J., Schwartz, E.S., 2002. Electricity prices and power derivatives: evidence from the Nordic power exchange. Review of Derivatives Research 5, 5-50.

Misiorek, A., Trück, S., Weron, R., 2006. forecasting spot electricity prices with linear and non-linear time series models. Studies in Nonlinear Dynamics and Econometrics 10 (3) (Article 2).

Mount, T.D., Ning, Y., Cai, X., 2006. Predicting price spikes in electricity markets using a regime-switching model with time-varying parameters. Energy Economics 28 (1), 62-80.

Mugele, Ch., Rachev, S.T., Trück, S., 2005. Stable modeling of different European power markets. Investment Management and Financial Innovations 2005/3, 65-85.

Musiela, M., Rutkowski, M., 1997. Martingale Methods in Financial Modelling. Springer-Verlag, Berlin.

Nord Pool, 2006. Trade at the Nordic Spot Market. Nord Pool Spot AS.

Oliver, J.E., Hidore, J.J., 2001. Climatology: An Atmospheric Science, 2 edition. Prentice Hall.

Park, H., Mjelde, J.W., Bessler, D.A., 2006. Price dynamics among U.S. electricity spot markets. Energy Economics 28 (1), 81-101.

Perello, J., Montero, M., Palatella, L., Simonsen, I., Masoliver, J., 2006. Entropy of the Nordic electricity market: anomalous scaling, spikes, and mean-reversion. Journal of Statistical Mechanics: Theory and Experiment P11011.

Pilipovic, D., 1998. Energy Risk: Valuing and Managing Energy Derivatives. McGraw-Hill, New York.

Pindyck, R., 1999. The long-run evolution of energy prices. Energy Journal 20, 1-27.

Pindyck, R., 2001. The dynamics of commodity spot and futures markets: a primer. Energy Journal 22 (3), 1-29.

Rachev, S.T., Trück, S., Weron, R., 2004. Risk management in power markets (Part III): advanced spot price models and VaR approaches. RISKNEWS 05/2004, pp. 67-71 (in German).

Shahidehpour, M., Yamin, H., Li, Z., 2002. Market Operations in Electric Power Systems: Forecasting, Scheduling, and Risk Management. Wiley.

Simonsen, I., 2003. Measuring anti-correlations in the Nordic electricity spot market by wavelets. Physica A 322, 597-606.

Simonsen, I., 2005. Volatility of power markets. Physica A 355, 10-20.

Skantze, P.L., Ilic, M.D., 2001. Valuation, Hedging and Speculation in Competitive Electricity Markets: A Fundamental Approach. Kluwer Academic Publishers.

Stevenson, M., 2001. Filtering and Forecasting Spot Electricity Prices in the Increasingly Deregulated Australian Electricity Market. Research Paper, vol. 63. Quantitative Finance Research Centre, University of Technology, Sydney.

Tol, R.S.J., 1996. Autoregressive conditional heteroskedasticity in daily temperature measurements. Environmetrics 7, 67-75.

Vasicek, O., 1977. An equilibrium characterization of the term structure. Journal of Financial Economics 5, $177-188$.

Vahviläinen, I., Pyykkönen, T., 2005. Stochastic factor model for electricity spot price — the case of the Nordic market. Energy Economics 27 (2), 351-367.

Ventosa, M., Baillo, A., Ramos, A., Rivier, M., 2005. Electricity market modeling trends. Energy Policy 33 (7), 897-913.

Villaplana, P., 2003. Pricing Power Derivatives: A Two-factor Jump-diffusion Approach. Working Paper 03-18 Universidad Carlos III de Madrid.

Weron, R., 2002. Measuring long-range dependence in electricity prices. In: Takayasu, H. (Ed.), Empirical Science of Financial Fluctuations. Springer, Tokyo, pp. 110-119.

Weron, R., 2006. Modeling and Forecasting Electricity Loads and Prices: A Statistical Approach. Wiley, Chichester.

Weron, R., Kozłowska, B., Nowicka-Zagrajek, J., 2001. Modeling electricity loads in California: a continuous time approach. Physica A 299, 344-350.

Weron, R., Simonsen, I., Wilman, P., 2004. Modeling highly volatile and seasonal markets: evidence from the Nord Pool electricity market. In: Takayasu, H. (Ed.), The Application of Econophysics. Springer, Tokyo, pp. 182-191. 